
ALL CLINICAL STUDIES TO DATE

Caroline Gordon ${ }^{1}$, Roberto Bassi ${ }^{2}$, Peter Chang ${ }^{2}$, Amy Kao ${ }^{2}$, David Jayne ${ }^{3}$, David Wofsy ${ }^{4}$, Victor Ona ${ }^{2}$, Patricia Fleuranceau-Morel ${ }^{2}$. ${ }^{1}$ University of Birmingham, Birmingham, United Kingdom; ${ }^{2}$ EMD Serono Research and Development Institute, Inc., Billerica, United States of America; ${ }^{3}$ University of Cambridge, Cambridge, United Kingdom; ${ }^{4}$ University of California, San Francisco, United States of America

Background: We conducted an integrated analysis of pooled safety data from all 17 atacicept clinical studies across multiple indications to date. Objectives: To characterize the overall safety profile of atacicept. Methods: Analyses were based on 3 pooled datasets: double-blind placebo (PBO)-controlled set (DBPC-S) $(n=1568$; key endpoint: treatmentemergent AEs [TEAEs]); systemic lupus erythematosus set (SLE-S; $n=761$; key endpoints: IgG change and serious infection rates, and mortality); and full analysis set (FA-S; $n=1845$; key endpoint: exposureadjusted mortality).

Results: Of 1568 patients (DBPC-S), 30.8\% received PBO, and $8.2 \%$, $24.5 \%$ and $36.5 \%$ received atacicept 25,75 and $150 \mathrm{mg}$. Overall, baseline characteristics were balanced across treatment arms. Treatment exposure in patient-years (py) was similar with PBO and atacicept 75 and $150 \mathrm{mg}$ but was lower with $25 \mathrm{mg}$ (Table). Exposure-adjusted TEAE rates were generally higher with atacicept vs PBO; serious TEAE and infection rates were similar with atacicept and PBO (Table). TEAE-related discontinuation rates were higher with atacicept vs PBO (16.1 vs 10.9/ $100 \mathrm{py}$ ). In the SLE-S and DBPC-S, pharmacodynamic effects of atacicept (eg on lgG) were not associated with an increase in infection rates. Across all studies (FA-S), 11 patients died during treatment. Across all indications, exposure-adjusted mortality rates/100 py $(95 \% \mathrm{Cl})$ were 3.60 $(0.90-14.38), 0.34(0.05-2.43), 1.18(0.49-2.82)$ for atacicept 25,75 and $150 \mathrm{mg}$, and $0.44(0.06-3.12)$ for PBO. In SLE patients, exposureadjusted mortality rates/100 py were $1.45(0.54-3.87)$ with atacicept 150 $\mathrm{mg}$ and $0.78(0.29-2.07)$ across all atacicept-treated patients. The underlying disease and other causes were potential confounders in most cases.

Conclusion: In this integrated safety analysis of atacicept, no consistent association was found between atacicept dose and specific TEAEs or mortality. These results support further development and evaluation of atacicept in patients in whom potential benefits may outweigh risks.

Table.Exposure-adjusted TEAE rates by dose (DBPC-S)

\begin{tabular}{|c|c|c|c|c|c|c|}
\hline & \multirow{2}{*}{$\begin{array}{l}\text { Placebo, } \\
n=483\end{array}$} & \multicolumn{4}{|c|}{ Atacicept } & \multirow{2}{*}{$\begin{array}{r}\text { Total, } \\
-\mathrm{n}=1568\end{array}$} \\
\hline & & $\begin{array}{l}25 \mathrm{mg}, \\
\mathrm{n}=129\end{array}$ & $\begin{array}{l}75 \mathrm{mg}, \\
\mathrm{n}=384\end{array}$ & $\begin{array}{c}150 \mathrm{mg}, \\
\mathrm{n}=572\end{array}$ & $\begin{array}{c}\text { All, } \\
n=1085\end{array}$ & \\
\hline $\begin{array}{l}\text { Total number of py } \\
\text { TEAE, } \mathbf{n} \text { (rate per } 100 \text { py) }\end{array}$ & 278.3 & 51.5 & 225.0 & 286.7 & 563.2 & 841.4 \\
\hline Hypersensitivity & $37(13.9)$ & $8(15.7)$ & $\begin{array}{c}40 \\
(19.1)\end{array}$ & $55(20.4)$ & $\begin{array}{c}103 \\
(19.4)\end{array}$ & $\begin{array}{c}140 \\
(17.6)\end{array}$ \\
\hline Infections & $\begin{array}{c}211 \\
(107.8)\end{array}$ & $\begin{array}{c}43 \\
(104.4)\end{array}$ & $\begin{array}{c}180 \\
(118.7)\end{array}$ & $\begin{array}{c}281 \\
(141.3)\end{array}$ & $\begin{array}{c}504 \\
(128.7)\end{array}$ & $\begin{array}{c}715 \\
(121.7)\end{array}$ \\
\hline Serious infection & $20(7.3)$ & $1(1.9)$ & $\begin{array}{c}23 \\
(10.5)\end{array}$ & $22(7.7)$ & $46(8.3)$ & $66(7.9)$ \\
\hline Severe infection & $9(3.2)$ & 0 & $11(4.9)$ & $16(5.6)$ & $27(4.8)$ & $36(4.3)$ \\
\hline Herpes zoster & $13(4.7)$ & $2(3.9)$ & $10(4.5)$ & $17(6.1)$ & $29(5.2)$ & $42(5.1)$ \\
\hline Injection site reactions & $54(20.9)$ & $\begin{array}{c}27 \\
(64.8)\end{array}$ & $\begin{array}{l}109 \\
(63.0)\end{array}$ & $\begin{array}{c}156 \\
(72.4)\end{array}$ & $\begin{array}{c}292 \\
(67.9)\end{array}$ & $\begin{array}{c}346 \\
(50.2)\end{array}$ \\
\hline $\begin{array}{l}\text { Severe } \\
\text { hypogammaglobulinemia } \\
(\operatorname{lgG}<3 \mathrm{~g} / \mathrm{L})\end{array}$ & 0 & 0 & $2(0.9)$ & $4(1.4)$ & $6(1.1)$ & $6(0.7)$ \\
\hline Cardiac arrhythmias [all] & $18(6.6)$ & $\begin{array}{c}11 \\
(22.4)\end{array}$ & $\begin{array}{c}23 \\
(10.6)\end{array}$ & $25(8.9)$ & $\begin{array}{c}59 \\
(10.8)\end{array}$ & $77(9.4)$ \\
\hline Ventricular arrhythmias & $5(1.8)$ & 0 & $4(1.8)$ & $6(2.1)$ & $10(1.8)$ & $15(1.8)$ \\
\hline Ischemic heart disorders & $11(4.0)$ & $3(5.9)$ & $13(5.9)$ & $11(3.9)$ & $27(4.9)$ & $38(4.6)$ \\
\hline $\begin{array}{l}\text { Embolic and } \\
\text { thromboembolic events }\end{array}$ & $11(4.0)$ & $1(2.0)$ & $6(2.7)$ & $9(3.2)$ & $16(2.9)$ & $27(3.2)$ \\
\hline Vestibular disorders & $19(7.0)$ & $5(9.9)$ & $18(8.3)$ & $26(9.3)$ & $49(8.9)$ & $68(8.3)$ \\
\hline Demyelination & $1(0.4)$ & $1(1.9)$ & 0 & $5(1.7)$ & $6(1.1)$ & $7(0.8)$ \\
\hline Depression & $14(5.1)$ & $3(5.8)$ & $8(3.6)$ & $11(3.9)$ & $22(3.9)$ & $36(4.3)$ \\
\hline Malignant tumor & 0 & $1(1.9)$ & $1(0.4)$ & $3(1.1)$ & $5(0.9)$ & $5(0.6)$ \\
\hline Serious TEAE & $51(18.9)$ & $\begin{array}{c}15 \\
(30.0)\end{array}$ & $\begin{array}{c}51 \\
(23.9)\end{array}$ & $61(21.8)$ & $\begin{array}{c}127 \\
(23.4)\end{array}$ & $\begin{array}{c}178 \\
(21.9)\end{array}$ \\
\hline Severe TEAE & $28(10.2)$ & $\begin{array}{c}10 \\
(19.6)\end{array}$ & $\begin{array}{c}45 \\
(20.9)\end{array}$ & $56(20.0)$ & $\begin{array}{c}111 \\
(20.3)\end{array}$ & $\begin{array}{c}139 \\
(17.0)\end{array}$ \\
\hline $\begin{array}{l}\text { Discontinuation of } \\
\text { treatment due to TEAE }\end{array}$ & $30(10.9)$ & $\begin{array}{c}14 \\
(27.6)\end{array}$ & $\begin{array}{c}30 \\
(13.4)\end{array}$ & $46(16.1)$ & $\begin{array}{c}90 \\
(16.1)\end{array}$ & $\begin{array}{c}120 \\
(14.3)\end{array}$ \\
\hline Infection-related deaths, $\mathrm{r}$ & (\%) & & & & & \\
\hline Deaths & 0 & 0 & 0 & $2(0.3)^{*}$ & 0 & 0 \\
\hline
\end{tabular}

alveolar hemorrhage $(n=1)$
Disclosure of Interests: Caroline Gordon Grant/research support from: Sandwell and West Birmingham Hospitals NHS Trust have received funding from UCB to support research work done by my research group that was unrelated to any pharmaceutical product or clinical trial., Consultant for: I have provided consultancy advice and taken part in scientific advisory boards on the design and analysis of clinical trials and the management of lupus for GSK, EMD Serono and UCB. I have taken part in adjudication and safety monitoring committees for BMS., Speakers bureau: I have been paid by UCB for speaking at meetings., Roberto Bassi Employee of: Current employees of EMD Serono, Peter Chang Employee of: Current employees of EMD Serono, Amy Kao Employee of: Current employees of EMD Serono, David Jayne Grant/research support from: David Jayne has received research grants from Chemocentryx, GSK, Roche/Genentech and Sanofi-Genzyme. He has received consultancy fees from Astra-Zeneca, Boehringer-Ingelheim, Chemocentryx, Chugai, GSK, Infla-RX, Insmed and Takeda, David Wofsy Consultant for: GlaxoSmithKline - Member, data safety monitoring board

Novartis - Member, data safety monitoring board

Celgene - member, scientific advisory board, Victor Ona Employee of: Current employees of EMD Serono, Patricia Fleuranceau-Morel Employee of: Current employees of EMD Serono

DOI: 10.1136/annrheumdis-2019-eular.703

\section{FRI0195 EFFICACY AND SAFETY OF DAPIROLIZUMAB PEGOL (DZP) IN PATIENTS WITH MODERATELY TO SEVERELY ACTIVE SYSTEMIC LUPUS ERYTHEMATOSUS (SLE): A RANDOMISED, PLACEBO (PBO)-CONTROLLED STUDY}

Richard Furie $^{1}$, lan N. Bruce ${ }^{2}$, Thomas Dörner ${ }^{3}$, Manuel Gustavo Leon ${ }^{4}$, Piotr Leszczynski ${ }^{5}$, Murray B. Urowitz ${ }^{6}$, Birgit Haier ${ }^{7}$, Teri Jimenez ${ }^{8}$,

Catherine Barbey ${ }^{9}$, Jiajun Liu ${ }^{10}$, Christian Stach ${ }^{7}{ }^{1}$ Northwell Health, Great Neck, United States of America; ${ }^{2}$ University of Manchester, Manchester, United Kingdom; ${ }^{3}$ Charite Berlin, Berlin, Germany; ${ }^{4}$ Investigaciones Clínicas, Lima, Peru; ${ }^{5}$ Poznan University of Medical Sciences, Poznan, Poland; ${ }^{6}$ Toronto Western Hospital, Toronto, Canada; ${ }^{7}$ UCB Pharma, Monheim, Germany, ${ }^{8}$ UCB Pharma, Raleigh, United States of America; ${ }^{9}$ Biogen, Baar, Switzerland; ${ }^{10}$ Biogen, Cambridge, United States of America

Background: $C D 40$ ligand (CD40L) regulates interactions between $T$ cells and CD40-expressing cells including antigen-presenting cells (APC) and B cells, thereby playing a critical role in autoimmune disease pathogenesis. DZP, a PEGylated monovalent Fab' antibody fragment with specificity for CD40L, prevents $\mathrm{CD} 40 \mathrm{~L}$ engagement of $\mathrm{CD} 40$ and thus blocks intracellular signalling and APC activation.

Objectives: To report the 24-week efficacy and safety interim data of DZP in a phase Illb, randomised, double-blind, PBO-controlled, dose-ranging study in patients with SLE (NCT02804763).

Methods: Patients with moderately to severely active SLE (SLEDAI-2K score $\geq 6$; $\geq 1$ BILAG grade $A$ or $\geq 2$ BILAG grade $B$ organ domain scores at screening) despite stable non-biologic standard of care treatment were randomised 1:1:1:1 to receive iv DZP 6,24 or $45 \mathrm{mg} / \mathrm{kg}$ or PBO every 4 weeks for 20 weeks. Patients receiving corticosteroids (CS) $>10 \mathrm{mg} /$ day prednisone equivalent were required to start tapering CS by Week 4; guidance was provided, but tapering schedules were ultimately determined by the investigators. The primary objective was to establish a dose-response relationship across three doses of DZP and PBO based on BICLA response rates at Week 24. Four pre-specified dose-response models were tested by a statistical method (MCP-Mod), to determine whether any of the models fit the observed data with statistical significance (at a one-sided $\mathrm{p} \leq 0.05$ ). The secondary endpoint was a pairwise comparison of BICLA response rates at Week 24. Other endpoints included the SRI-4 and BICLA response rates at 12 and 24 weeks, mean changes from baseline in SLEDAl-2K scores at 12 and 24 weeks, percentage of patients with daily CS dose $\leq 7.5 \mathrm{mg} /$ day at 12 and 24 weeks, pharmacodynamic (PD) markers and safety.

Results: 182 patients were randomised; 167 (91.8\%) completed Week 24 of the study. Baseline demographics were similar across treatment groups. The primary endpoint was not met as none of the pre-specified dose-response models fit the observed BICLA response rates at Week 24 with statistical significance $(p=0.06$ for the most applicable model). BICLA response rates and other efficacy outcome measures at Weeks 12 and 24, were numerically higher for all DZP groups vs PBO (Table 1). Favourable biological effects were observed with improvements in relevant PD markers, including anti-dsDNA antibody levels, in DZP groups vs PBO. Treatment-emergent adverse events (TEAEs) and serious TEAEs were generally balanced across treatment groups (Table 2). More upper 
respiratory tract infections were observed in patients treated with DZP vs PBO; the majority were mild. We observed four thromboembolic events: one in the $24 \mathrm{mg} / \mathrm{kg}$ DZP group and three in the PBO group.

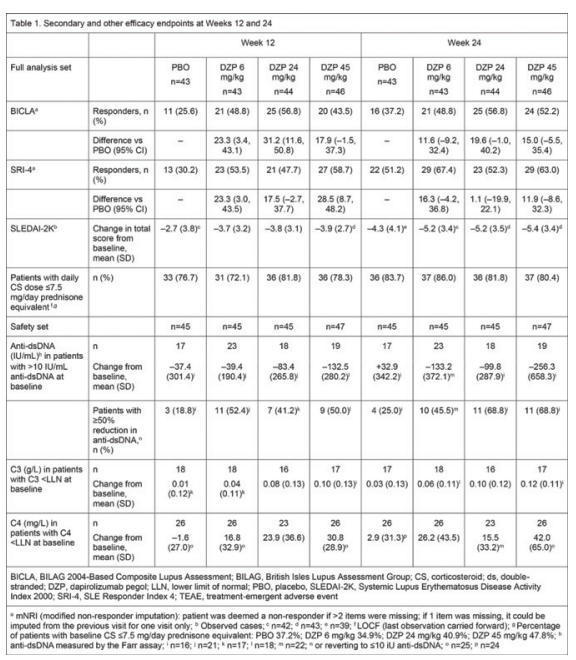

\begin{tabular}{|c|c|c|c|c|}
\hline & $\begin{array}{l}\text { PBO } \\
n=45\end{array}$ & $\begin{array}{l}\mathrm{DZP} 6 \mathrm{mg} / \mathrm{kg} \\
\quad \mathrm{n}=45\end{array}$ & $\begin{array}{c}\mathrm{DZP} 24 \\
\mathrm{mg} / \mathrm{kg} \\
\mathrm{n}=45\end{array}$ & $\begin{array}{l}\mathrm{DZP} 45 \\
\mathrm{mg} / \mathrm{kg} \\
\mathrm{n}=47\end{array}$ \\
\hline Serious TEAEs, $n$ (\%) & $5(11.1)$ & $1(2.2)$ & $4(8.9)$ & $3(6.4)$ \\
\hline TEAEs of interest, $n(\%)$ & $9(20.0)$ & $8(17.8)$ & $11(24.4)$ & $9(19.1)$ \\
\hline $\begin{array}{l}\text { Thromboembolic } \\
\text { events }\end{array}$ & $3(6.7)$ & 0 & $1(2.2)$ & 0 \\
\hline $\begin{array}{l}\text { Moderate to } \\
\text { severe infections }\end{array}$ & $6(13.3)$ & $8(17.8)^{a}$ & $11(24.4)$ & $8(17.0)$ \\
\hline \multicolumn{5}{|c|}{$\begin{array}{l}\text { DZP, dapirolizumab pegol; PBO, placebo, TEAE, treatment-emergent adverse event } \\
\text { a One TEAE was of mild intensity but was deemed to be a TEAE of interest by the } \\
\text { investigator for the interim analysis }\end{array}$} \\
\hline
\end{tabular}

Conclusion: DZP appeared to be well tolerated as TEAEs were generally balanced across the treatment groups. Numerically greater improvements relative to PBO were observed consistently across multiple efficacy endpoints and biomarkers; however, for the primary endpoint no pre-specified dose-response relationship model fit the observed BICLA response rates at Week 24 with statistical significance. The potential for deriving clinical benefit from DZP in patients with SLE warrants further investigation.

Acknowledgement: Supported by UCB Pharma and Biogen.

Disclosure of Interests: Richard Furie Grant/research support from: Biogen, UCB Pharma, but not in the last 12 months, Consultant for: Biogen, UCB Pharma, but not in the last 12 months, lan N. Bruce Grant/research support from: Genzyme Sanofi, GlaxoSmithKline, Consultant for: AstraZeneca, Eli Lilly, GlaxoSmithKline, ILTOO Pharma, Medlmmune, Merck Serono, Speakers bureau: GlaxoSmithKline, UCB Pharma, Thomas Dörner Grant/research support from: Eli Lilly, Janssen, Roche, UCB Pharma, Consultant for: Eli Lilly, Janssen, Roche, UCB Pharma, Speakers bureau: Eli Lilly, Janssen, Manuel Gustavo Leon: None declared, Piotr Leszczynski Grant/research support from: AbbVie, Amgen, Bristol-Myers Squibb, Immupharma, Janssen Cilag, Novartis, Roche, UCB Pharma, Consultant for: AbbVie, Amgen, Berlin Chemie, Eli Lilly, Novartis, Roche, Sandoz, UCB Pharma, Speakers bureau: AbbVie, Amgen, Berlin Chemie, Eli Lilly, Novartis, Roche, Sandoz, UCB Pharma, Murray B Urowitz Grant/research support from: GSK, Consultant for: BMS, Celgene, GSK, Lilly, UCB, Birgit Haier Shareholder of: UCB Pharma, Employee of: UCB Pharma, Teri Jimenez Employee of: UCB Pharma, Catherine Barbey Shareholder of: Biogen, Employee of: Biogen, Jiajun Liu Employee of: Biogen, Christian Stach Shareholder of: UCB Pharma, Employee of: UCB Pharma DOI: 10.1136/annrheumdis-2019-eular.5529

\section{FRI0196 \\ TREATMENT OF SYSTEMIC LUPUS ERYTHEMATOSUS PATIENTS WITH THE IMMUNOPROTEASOME INHIBITOR KZR-616: RESULTS FROM THE FIRST 2 COHORTS OF AN OPEN-LABEL PHASE 1B DOSE ESCALATION TRIAL}

Richard Furie ${ }^{1}$, Darrin Bomba ${ }^{2}$, Maria Dall'era ${ }^{3}$, Massiel Prieto ${ }^{4}$, Janet Anderl ${ }^{2}$, Jinhai Wang ${ }^{2}$, Christopher Kirk', Niti Goel ${ }^{2,5} .{ }^{1}$ Northwell Health, Great Neck, NY, United States of America; ${ }^{2}$ Kezar Life Sciences, South San Francisco, CA, United States of America; ${ }^{3}$ University of California San Francisco, San Francisco, CA, United States of America; ${ }^{4}$ Hope Clinical Trials, Miami, FL, United States of America; ${ }^{5}$ Duke University School of Medicine, Durham, NC, United States of America

Background: Nonspecific proteasome inhibitors, e.g., bortezomib (BTZ), target both the constitutive and immuno- proteasomes and are standard of care for multiple myeloma. While BTZ has been used to treat refractory systemic lupus erythematosus (SLE) and lupus nephritis (LN), it is associated with adverse events (AEs) that limit its broad use. KZR-616, a first-in-class selective inhibitor of the immunoproteasome, is highly active and well tolerated in murine $\mathrm{SLE}^{1}$. In a Phase $(\mathrm{Ph}) 1$ healthy volunteer (HV) study, KZR-616 subcutaneously (SC) at 30 and $45 \mathrm{mg}$ weekly (QW) was shown to be safe, be well tolerated and achieve the target level of immunoproteasome inhibition ${ }^{2}$. We report here the preliminary safety and efficacy of KZR-616 in the Ph 1b portion of Study KZR616-002 in active SLE patients (pts) (NCT03393013).

Objectives: The $1^{\circ}$ objective of this first-in-patient study is to assess the safety and tolerability of KZR-616. The $2^{\circ}$ objectives are to evaluate pharmacokinetics (PK) and determine the KZR-616 doses for the Ph 2 portion of the study. Pharmacodynamics (PD) and efficacy are also being assessed.

\begin{tabular}{|l|l|c|c|}
\hline $\begin{array}{l}\text { Assessments } \\
\text { Mean (SD) }\end{array}$ & Timepoint & $\begin{array}{c}\text { Cohort 1 } \\
\mathbf{n = 6}\end{array}$ & $\begin{array}{c}\text { Cohort 2 } \\
\mathbf{n}=3\end{array}$ \\
\hline \multirow{3}{*}{ SLEDAI } & BL & $9.7(1.97)$ & $10.0(2.00)$ \\
\cline { 2 - 4 } & W13 & $7.2(3.35)$ & $6.0(2.83)$ \\
\hline \multirow{3}{*}{ CLASI } & BL & $5.5(2.07)$ & $7.3(1.16)$ \\
\cline { 2 - 4 } TJC & W13 & $3.6(1.95)$ & $4.5(2.12)$ \\
\hline \multirow{3}{*}{ SJC } & BL & $14.3(8.14)$ & $11.7(4.93)$ \\
\cline { 2 - 4 } & W13 & $7.6(6.99)$ & $8.5(3.54)$ \\
\hline \multirow{3}{*}{ PhGA } & BL & $11.0(6.03)$ & $9.3(3.06)$ \\
\cline { 2 - 4 } & W13 & $4.4(6.07)$ & $3.5(4.95)$ \\
\hline \multirow{3}{*}{ PtGA } & BL & $58.3(19.24)$ & $63.3(26.50)$ \\
\cline { 2 - 4 } & W13 & $39.8(24.67)$ & $40.0(14.14)$ \\
\cline { 2 - 4 } & BL & $57.5(25.79)$ & $73.3(11.59)$ \\
\hline & W13 & $43.6(31.64)$ & $35.0(7.07)$ \\
\hline
\end{tabular}

Methods: This open-label multicenter dose escalation trial enrolled SLE pts (per Systemic Lupus International Collaborating Clinics Classification Criteria) with SLE Disease Activity Index (SLEDAI) $\geq 4$ despite stable background immunosuppressant, antimalarial, and/or corticosteroid ( $\leq 20 \mathrm{mg}$ prednisone equivalent) therapy. Patients received KZR-616 at $45 \mathrm{mg}$ (Cohort 1) or $60 \mathrm{mg}$ (Cohort 2) SC QW through Week 13 (W13) with 12 weeks of follow up. Cohort $2 a$ is currently enrolling pts using intrapatient dose escalation from 30 to $60 \mathrm{mg}$. Safety data include AEs, vitals, electrocardiograms and laboratory tests. Efficacy measures include the SLEDAI, Cutaneous Lupus Erythematosus Disease Area and Severity Index (CLASI), 28 tender (T) and swollen (S) joint counts (JC), Physician Global Assessment (PhGA), and Patient Global Assessment (PtGA) in evaluable pts (receive $\geq 1$ month of KZR-616; non-evaluable pts can be replaced).

Results: We enrolled 13 pts: 8 in Cohort 1, 5 in Cohort 2. The pts were $100 \%$ female; Baseline $(B L)$ median SLEDAl was 10.0. All pts received at least 1 dose of KZR-616. In each cohort, 3 pts withdrew due to withdrawal of consent prior to $W 13$. Overall, the $45 \mathrm{mg}$ dose was well tolerated with no SAEs; all AEs were mild in intensity. The most common AEs were injection site erythema (62.5\%), nausea (25\%), and injection site pruritus (25\%).Cohort $2(60 \mathrm{mg})$ enrollment was halted, as all pts experienced vomiting within 8-24 hours (h) of their first dose, which typically resolved within $24 \mathrm{~h}$. One pt had an SAE of thrombotic microangiopathy. Two pts permanently reduced their dose to $45 \mathrm{mg}$. After 2 doses at $45 \mathrm{mg}$, another pt successfully re-escalated to $60 \mathrm{mg}$. In 